\title{
Assessment of African Blackwood (Dalbergia melanoxylon) Population Structure in Kilwa District, Tanzania
}

\author{
Agnes M.S. Nyomora ${ }^{1}$, Washa B. Washa ${ }^{2^{*}}$, and Stephen I. Nnungu ${ }^{1}$ \\ ${ }^{I}$ Botany Department, College of Natural and Applied Sciences, University of Dar es Salaam, P. O. \\ Box 35060 Dar es Salaam, Tanzania \\ ${ }^{2}$ Mkwawa University College of Education, University of Dar es Salaam, P. O. Box 2513 Iringa, \\ Tanzania \\ Emails: agnesnyomora@gmail.com; wbugalama@yahoo.com;nnunguh@gmail.com \\ *Corresponding author
}

Received 21 Jun 2021, Revised 27 Sep 2021, Accepted 29 Sep 2021, Published Oct 2021

DOI: https://dx.doi.org/10.4314/tjs.v47i4.10

\begin{abstract}
Overharvesting and limited conservation efforts have posed a serious threat to future availability of Dalbergia melanoxylon in Tanzania in recent years. The study was conducted between 2018 and 2020 covering Mitarure Forest Reserve (MFR) and 2 surrounding community forests of Ngea and Nambawala in Kilwa District. The purpose of the study was to assess the existing population status of the species in Tanzania. A total of 36 circular plots in Mitarure and 15 plots in each community forest were laid down. Data were recorded for the number of stems per plot, and then converted on per hectare basis where the basal area and densities per hectare were calculated. Data was disaggregated into 5 Diameter at Breast Height $(\mathrm{DBH})$ generated distribution classes ranging from DBH 0 to more than $45 \mathrm{~cm}$. The results revealed that, there was a contrast between the Mitarure Forest Reserve and community forests in terms of individual number of trees per unit area, basal area and densities. The numbers of stems per hectare for the species were found to be 16,10 and 8 stems/ha in Mitarure, Ngea and Nambawala forest, respectively. Dalbergia melanoxylon in Mitarure forest was normally distributed. The respective basal area was over $80 \mathrm{~m}^{2}$ per ha in Nambawala against over 60 in MFR and Ngea. The results suggest success of the communities in conserving the species after previous overharvest. Authorities should frequently visit forests to increase the population of the species and reduce unauthorised harvesting.
\end{abstract}

Keywords: Dalbegia melanoxylon, Population structure, Mitarure forest reserve, Ngea and Nambawala community forests.

\section{Introduction}

Dalbergia melanoxylon Guill and Perr (African blackwood), also known as music wood, African ebony, Zebrawood and Mpingo, is a flowering plant that belongs to Family Leguminoseae, sub-family Papilionoidea (Arbonnier 2004). The Genus Dalbergia includes species such as Dalbergia latifolia (rosewood), Dalbergia decipularis (tulipwood or tulip poplar) and Dalbergia retusa (cocobolo) which yield other famous timbers (Arbonnier 2004, Maundu and Tengnas 2005, Bekele-Tesemma 2007).

Initiatives of research on propagation and conservation started in the mid-1980 in Tanzania when overharvesting, very low germination and low seedling growth rate of $D$. melanoxylon were found to be serious threats for the future availability of the species (Mbuya 1994, Beale 1995, Fauna and Flora 1442 
International 1995, Sharman 1995, TTSA 1995). Initially, Mbuya (1994) reported on propagation and management of agricultural and pastoral communities including $D$. melanoxylon. Mbuya (1994) also investigated the State of knowledge about the conservation and cultivation status of the species in Tanzania, thus advancing UNEP, WWF and FFI's ideas to Tanzania government in the late 1980s to conserve the species. Beale (1995) and Sharman (1995) investigated the sustainable production and conservation of the species. While Beale (1995) investigated ecological economic approach of the species, Sharman (1995) was on "the sustainable management, Fauna and Flora International (1995) reported on conservation and responsible use of $D$. melanoxylon, while the Tanzania Tree Seed Agency (TTSA 1995) reported on storage conditions for long period viability of the species. The African Blackwood Conservation Project (ABCP) was established in 1996 as a result of the above efforts. Its purpose was to promote the population of the species, to sensitize the community on economic and ecological importance of the species, to involve the community in seedling production for propagation of the species and conduct researches on Mpingo.

Although D. melanoxylon was recorded as plentiful in Tanzania in the 1930s (Mbuya 1994), most sources indicated that the species is scattered in occurrence. In 1960s, it was recorded as being rare due to intensive exploitation and places that were under heaviest harvesting pressure were easily accessible, close to the major tourist markets for Makonde art and those near sawmills in Dar es Salaam, namely Lindi and Mtwara regions (Mbuya 1994). Also trees population continued to decrease due to over-exploitation and inadequate fire control measures (Mbuya 1994).

Unsustainable commercial harvesting of $D$. melanoxylon, forest clearing for settlements and agriculture, low regenerative ability of the species in the forest and lack of conservation efforts indicated serious threats to the future availability of $D$. melanoxylon (Washa et al. 2012). This has necessitated scientists to conduct population studies, inventory studies, population density studies and review of literature in every five to ten (5-10) years to evaluate the actual and existing population in areas where the species is reported to be abundant (Washa 2015. It is nineteen (19) years since the last population study and population density was conducted (Malimbwi et al. 2000), seventeen (17) years since last inventory study was taken (Opulukwa et al. 2002 Katani et al. 2016) and five (7) years since last literature review was reported on $D$. Melanoxylon (Washa 2014). The Mpingo Conservation Project has been conducting research and community-based conservation in the District since 1995, focusing on the valuable timber Dalbergia melanoxylon.

Hence, research on population structure of D. melanoxylon was found not only important but mandatory to build capacity on the species since the scientific findings will be the base for recommendations to the government. The main objective of this study was to investigate the population structure of $D$. melanoxylon in the Mitarure forest reserve located in Nachingwea district, Lindi Region and surrounding community forests in order to evaluate the standing volume and plant densities of the species; so as to give a good reflection of whether D. melanoxylon in Tanzania is still at low-risk near threatened, endangered or is about to extinction, and what should be done.

\section{Materials and Methods \\ Study sites}

This study was conducted in Kilwa District $\left(8^{\circ} 15^{\prime}-10^{\circ} 00^{\prime} \mathrm{S}, \quad 38^{\circ} 40^{\prime}-39^{\circ} 40^{\prime} \mathrm{E}\right)$ of Lindi Region. One forest, namely Mitarure Forest Reserve $\left(8^{\circ} 45^{\prime}-9^{\circ} 03^{\prime} \mathrm{N} 38^{\circ} 53^{\prime}-39^{\circ} 14^{\prime} \mathrm{E}\right)$ out of 11 forest reserves (Figure 1) in the district and two community forests of Ngea and Nambawala villages out of 5 surrounding registered villages in the district were sampled. The sites are within the Miombo woodland with ecological zone. 


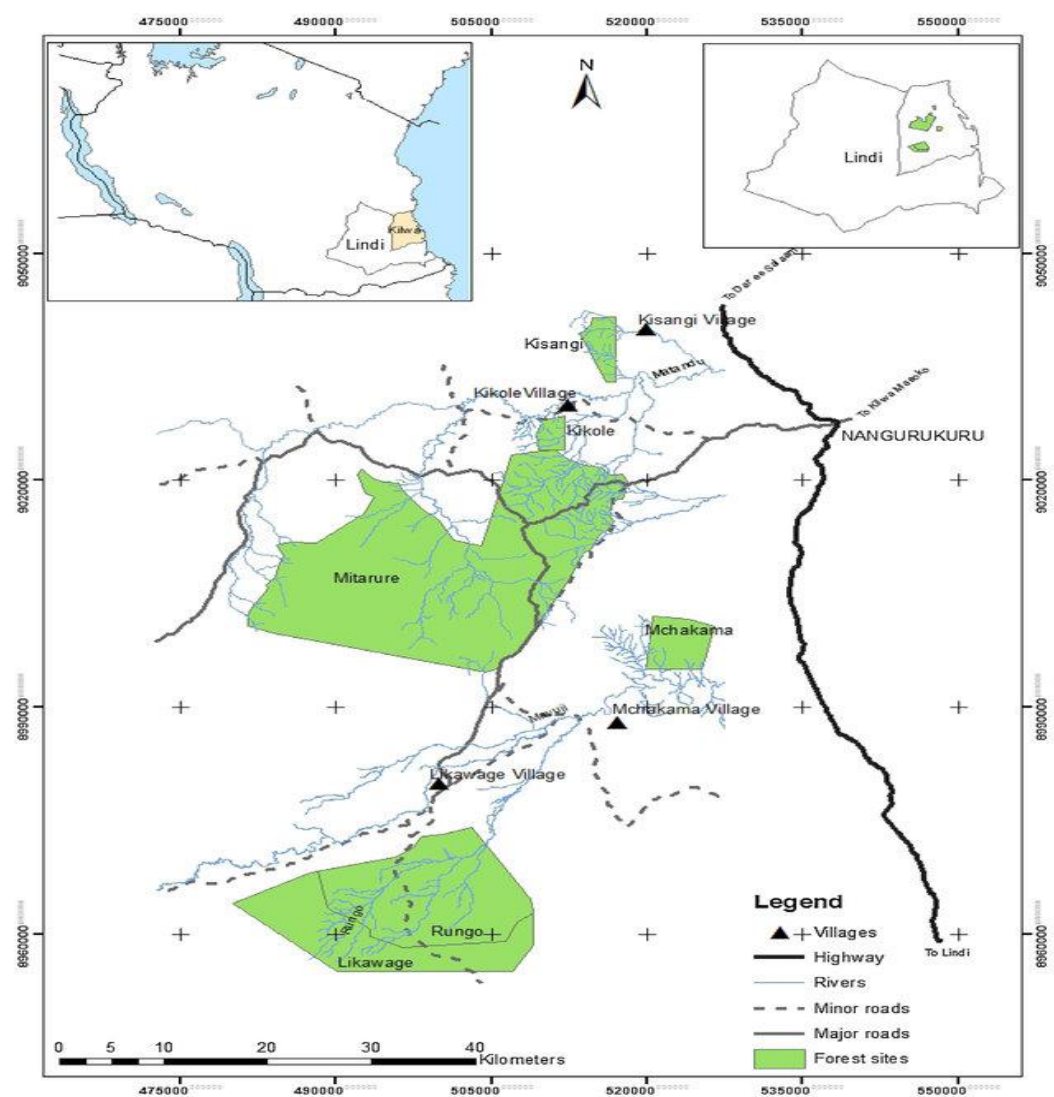

Figure 1: Study area showing Mitarure Forest Reserve (Source: Kalonga et al. 2016).

\section{Sampling and sampling design}

Purposive sampling procedure was employed in selecting quadrats for data collection. The reason for the selection of this design was based on the fact that, $D$. melanoxylon plants were scattered around Mitarure Forest Reserve and the nearby community forests of Ngea and Nambawala. A total of 36 circular plots were laid and established in Mitarure Forest Reserve, while 15 plots were for each community forest. The plots for the community forests were located at almost five kilometers away from the villages because the land near the villages was under cultivation.

The sample plots were circular with a radius of $20 \mathrm{~m}$. In each plot, all $D$. melanoxylon trees with $\mathrm{DBH}>4 \mathrm{~cm}$ were measured for $\mathrm{DBH}$ to the nearest $0.1 \mathrm{~cm}$ and total height to the nearest $0.1 \mathrm{~m}$ according to Arbonnier (2004). Due to multiple stems and flutes on the trees, standard mensuration techniques had to be followed strictly to minimize measurement errors. For example, for a tree forking below $1.3 \mathrm{~m}$ from the ground, each stem was treated as an individual tree. For trees with flutes, diameter was recorded as the average of two measurements taken at right angles. A basal area count was taken for all tree species using a Vernier caliper with a basal area factor of 1 .

In each plot demarcated, a total count of $D$. melanoxylon plants was made and each disaggregated into respective DBH. Diameter at breast height $(\mathrm{DBH})$ was measured in $\mathrm{cm}$ from the ground surface to $130 \mathrm{~cm}$ height using Vernier caliper.

The data was entered in Microsoft Excel to create data files and sorted to generate $\mathrm{DBH}$ 
class distributions, as well as stem densities. Furthermore, DBH values were categorized into 5 classes: Class 1: DBH 0-10 cm, Class 2: DBH 10.1-20 cm, Class 3: DBH 20.1-30 cm, Class 4: DBH 30.1-40 cm, Class 5: DBH $\geq 45$ $\mathrm{cm}$ according to Arbonnier (2004). Parameters determined include number of stems per plot, basal area per plot, volume and diameter class of trees.

\section{Number of stems}

The number of stems per hectare was calculated as follows: $\mathrm{N}=\mathrm{n} / \mathrm{A}$.

where, $\mathrm{N}=$ number of stems per plot; $\mathrm{n}=$ total number of trees in each DBH class, and $\mathrm{A}=$ total area of sampled plots. The number of plants per plot was then converted on a hectare basis.

\section{Basal area per hectare}

Basal area of a tree was calculated using the following formula:

$$
\text { gi }=\pi \times \mathrm{D}^{2} / 4
$$

While the basal area per hectare (BAH) was calculated as follows:

$$
\mathrm{G}=\sum \mathrm{gi} / \mathrm{A}
$$

Where: $\mathrm{G}=$ basal area per hectare $\left(\mathrm{m}^{2} / \mathrm{ha}\right) \mathrm{gi}=$ basal area of tree $\left(\mathrm{m}^{2}\right), \mathrm{n}=$ number of plots surveyed, $\mathrm{D}=$ diameter at breast height $(\mathrm{DBH})$, and $A=$ total area of sampled plots (ha) $\pi=$ 3.14 .

\section{Data analysis}

The trees were summarized in terms of the number of stems per hectare at different DBH size classes, basal area per hectare and density and these were compared among habitats using Analysis of Variance (ANOVA) (Graphpad Instat 2003).

\section{Results}

\section{Basal area}

Generally, the basal area/ha increased with increasing DBH in Nambawala community forest. The average basal area per hectare was found to be $160 \mathrm{~m}^{2}$ per ha in large trees with $\mathrm{DBH}$ of over $40 \mathrm{~cm}$ (Figures 2A and 2B). Likewise in Mitature forest reserve with $\mathrm{DBH}$ of over $80 \mathrm{~cm}$ (Figure 4B). In Ngea community forest, the $30-40 \mathrm{~cm} \mathrm{DBH}$ had the highest basal area/ha of over $65 \mathrm{~m}^{2}$.

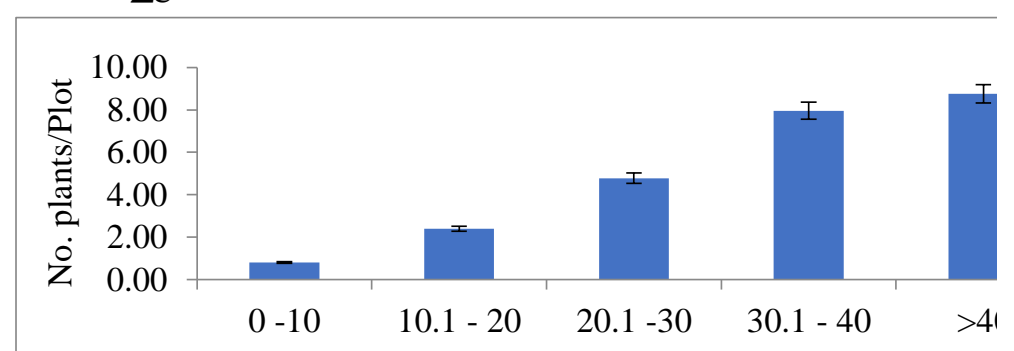

Figure 2A: Phenological Status of Mpingo in Nambawala Community Forest, Kilwa District.

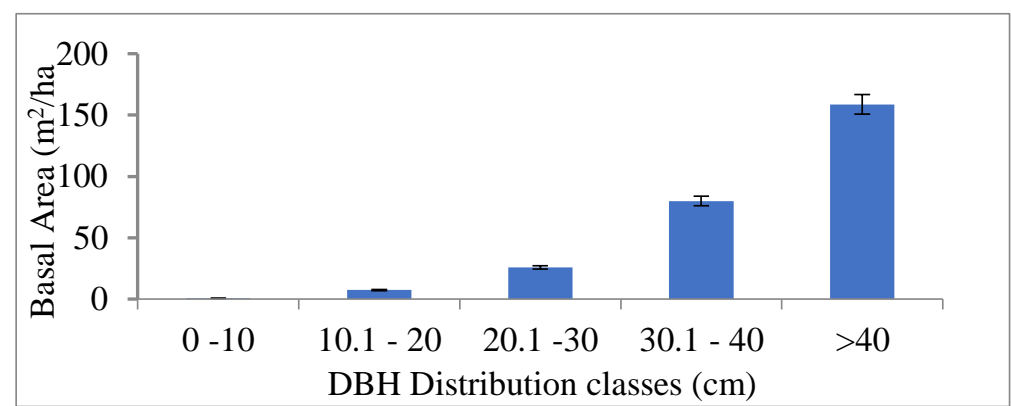

Figure 2B: Phenological Status of Mpingo in Nambawala Community Forest, Kilwa District. 


\section{Number of stems per hectare}

The results showed that the number of stems per hectare for the Dalbergia melanoxylon was found to be 16 stems/ha in Mitarure forest reserve, 10 stems/ha in Ngea and 8 stems/ha in Nambawala. The respective basal area was over $80 \mathrm{~m}^{2}$ per ha in Nambawala against over $60 \mathrm{~m}^{2}$ per ha in
Mitarure forest reserve and Ngea. Trees with intermediate diameters were scattered averaging 2-5 trees/plot. In Ngea community forest, over 8-10 tree/plot were associated with trees with DBH of between 10-30 cm (Figures $3 \mathrm{~A}$ and $3 \mathrm{~B}$ ) with fewer, less than 3 trees/plot being over $40 \mathrm{~cm} \mathrm{DBH}$.

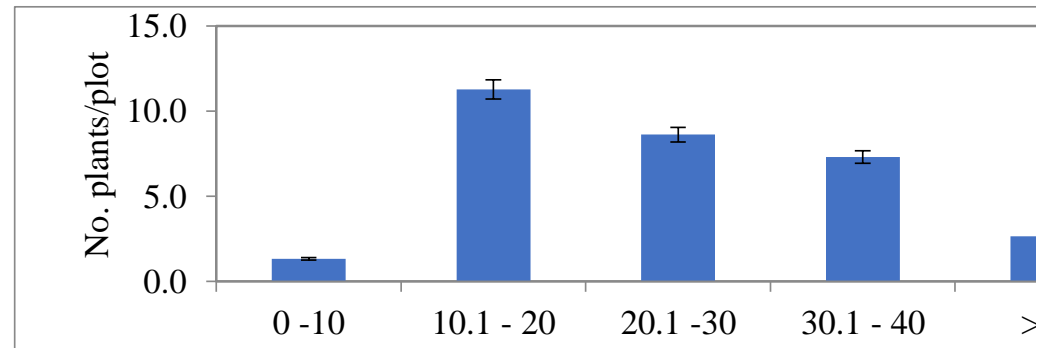

Figure 3A: Phenological status of mpingo in Ngea Community Forest, Kilwa District.

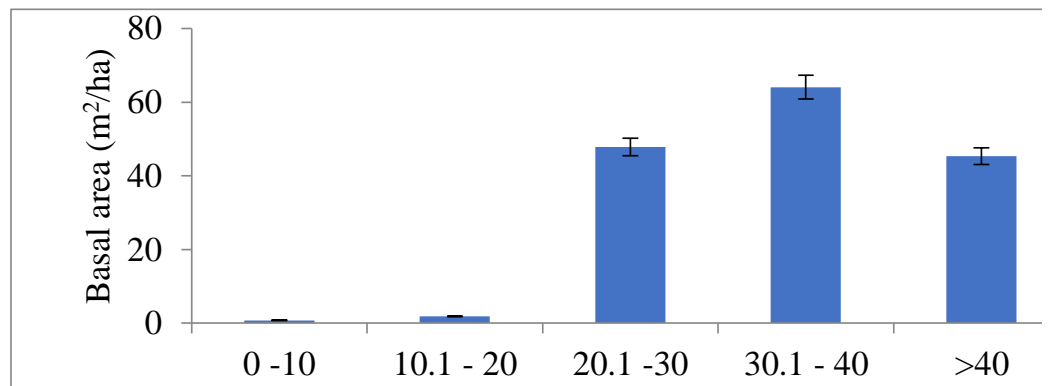

Figure 3B: Phenological status of mpingo in Ngea Community Forest, Kilwa District.

Dalbergia melanoxylon population in and larger mature trees estimated at 4-5 trees Mitature Forest Reserve was normally per ha being over $40 \mathrm{~cm}$ DBH. In all distributed whereby the highest number of community forests, the lowest number of plants of over 14-16 trees/plot were associated stems/plants per ha were associated with trees with trees with DBH of between $10-30 \mathrm{~cm}$ having the smallest DBH of less than $10 \mathrm{~cm}$ (Figure 4A and 4B). There was an appreciable indicative of low in-situ regeneration. number of seedlings of less than $10 \mathrm{~cm} \mathrm{DBH}$ )

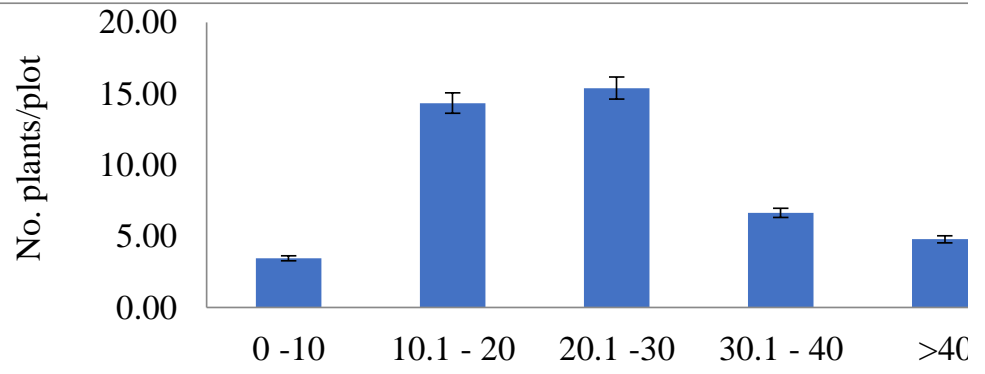

Figure 4A: Phenological status of mpingo in Mitature Forest Reserve, Kilwa District. 


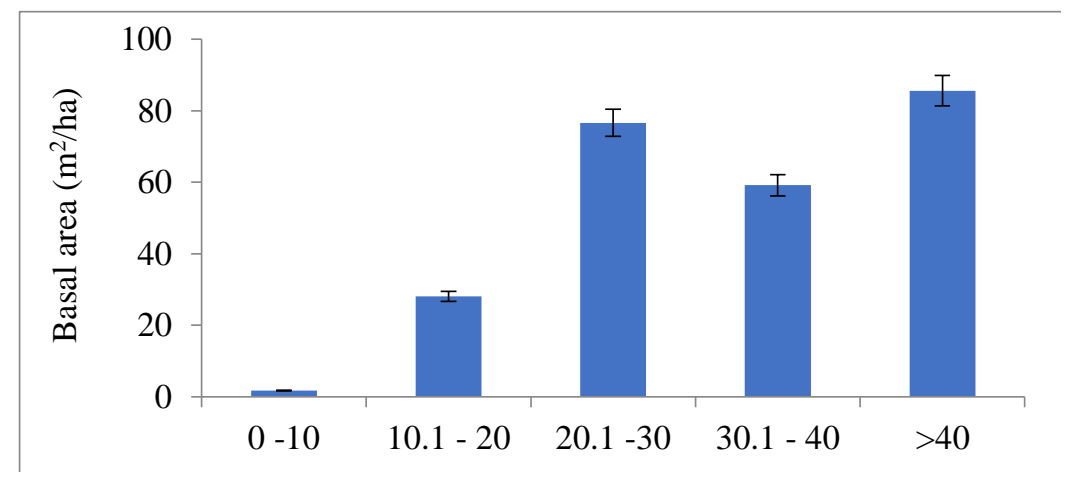

Figure 4B: Phenological status of mpingo in Mitature Forest Reserve, Kilwa District.

\section{Density}

Incremental yearly addition of $D$. melanoxylon heartwood is one reason for its notable density. The heartwood of the tree at $12 \%$ moisture content normally has a density of $1230-1330 \mathrm{~kg} / \mathrm{m}^{3}$, as compared to $997 \mathrm{~kg} / \mathrm{m}^{3}$ water density. A blackwood log will not float in water. The observed densities for forests in
Kilwa were as shown in Figure 5 where the trend showed that plants with low $\mathrm{DBH}$ also were lighter in the range of $50-60 \mathrm{~kg} / \mathrm{m}^{3}$, while larger trees with over $40 \mathrm{~cm}$ DBH had heavier densities of over $350 \mathrm{~kg} / \mathrm{m}^{3}$. Within the same DBH class, there were not much differences in densities between the reserve forest and community forests.

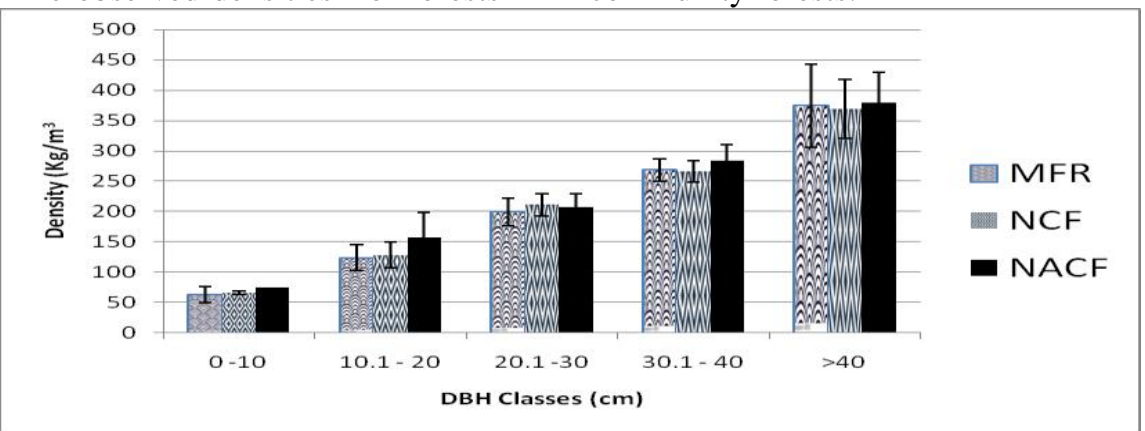

Figure 5: Densities of the African Blackwood in Reserves and Community Forests in Kilwa. MFR-Mitature Forest Reserve, NCF-Ngea Community Forest, NACF-Nambawala Community Forest.

\section{Discussion}

The analysis of DBH size class distribution of plant species among habitats is useful in understanding the population structure of the forests. The DBH size class distribution showed that most of the plant species had low DBH size class in Mitarure Forest Reserve. This is an indication that many tree populations were previously subjected to exploitation pressure with the resultant DBH size classes being skewed to the lowest size classes. Maundu and Tegnas (2005) pointed out that, small sized individuals in a given population function as a significant reserve for replacing older individuals. A skewed curve to lower DBH size classes (Figure 4) is an indication of community succession (Maundu and Tegnas). DBH size class variations among habitats show that tree populations are expanding with active recruitment at lower size classes that will replace ageing or dying trees in the forest. Tree species with DBH size classes above 40 $\mathrm{cm}$ were rare in Mitarure Forest Reserve. This is clearly an indication that anthropogenic 
activities affected the forest in the past. This was different in Nambawala community forest where most of the plant species had DBH size class of greater than $40 \mathrm{~cm}$. This is an indication that the community forest was protected from exploitation pressure for some times. By the time we were conducted this research, one of the companies was given a licence to harvest the matured trees. According to Arbonnier (2004), a regenerating population becomes stable when there is more recruitment of individuals at lower DBH sizes class declining subsequently to higher $\mathrm{DBH}$ size classes.

The number of stems did not show a true reversed J-shape in Nambawala due to controlled harvesting, imposed by the central government. In order to harvest $D$. melanoxylon tree, a permit is required from the District Forest Officer (DFO) who decides on the amount to be harvested. Most of the permits for harvesting were granted for Mitarure Forest Reserve and Ngea community forest for the past years. However, by the time we were conducting this research, the permits had started to be granted for Nambawala community forest.

The distribution of basal area per hectare had a J-shape common in natural forests (Maundu and Tegnas 2005). A similar trend was observed in Nambawala community forest and Mitarure Forest Reserve where basal areas increased with DBH. The DBH of many trees in Nambawala community forest were big to mid size trees compared to Mitarure Forest Reserve and Ngea community forest where there were few big size tree and mid size but numerous young seedling with DBH lower than $4 \mathrm{~cm}$. This suggests that there might be a relationship between forest density and $D$. melanoxylon regeneration. D. melanoxylon has been known as a light-demanding species; thus, it might not regenerate under heavy closed vegetation (Mbuya 1994, Washa 2008). Moreover, this is also the supporting evidence on the selective exploitation of this species from the reserve. Since there is prolific $D$. melanoxylon regeneration, the difference in stocking at older age may be attributed to ecological factors, fire and other growth conditions. The easy accessibility to public land, which enhances harvesting, may be another factor.

Presently, there are very few known plantations for D. melanoxylon where extraction occurs. Therefore, African wood market is currently sourced completely from natural forests such as Mitarure Forest Reserve and the nearby community forests. The study revealed that only the most mature with high $\mathrm{DBH}$ and the straightest trees are harvested from forest because of their market values. Therefore, the forest will remain with young and immature trees which results in ecologically out of balance with the minimal regenerative ability of the $D$. melanoxylon population due to lack of active reproductive trees. On the other hand, to balance the ecosystem, replanting of $D$. melanoxylon is vital. Sharman (1995) argued that, the slow growth rate of this species in the wild means reliance on only the natural reproductive capacity to replace those trees extracted, hence the future viability of the species as a commercial stock is questionable. Natural regeneration requires successful seed germination and growth as pointed out by Bekele-Tesemma (2007). However, individuals' survival chances are determined by the available limiting factors in both unprotected and protected areas. The study observed more abundant natural regrowth of seedlings in Mitarure Forest Reserve and Ngea community forest. This might be due to disturbances caused by wild animals and harvesting that lead to injured root suckers of D. melanoxylon.

\section{Conclusion}

Based on the results and the subsequent discussion, it is concluded that the population structure of $D$. melanoxylon had been adversely disturbed in Mitarure Forest Reserve and Ngea community forest due to over-exploitation especially in the past years compared to Nambawala community forest. It is 
recommended that regular patrols should be undertaken by the authority responsible with the management of the forest reserve and community forests to stop illegal harvests. It is also recommended to undertake enrichment planting of $D$. melanoxylon in the reserve, several times in order to balance the $D$. melanoxylon populations.

\section{Acknowledgements}

Authors are grateful for the financial support from the University of Dar es Salaam through its Competitive Research and Publication Grant of 2018/2019 under project number CoNASBT-18037. We are also grateful to Prof. Cosmas Mligo (the late) who assisted with the statistical analysis.

\section{References}

Arbonnier M 2004 Trees, shrubs and lianas of West Africa dry zones. CIRAD, Montpellier: Meseum National d"historie Naturelle, Paris.

Beale D 1995 "Tree"! What tree? An ecological economic approach to producing a sustainable mpingo trade. Master's thesis, University of Edinburgh.

Bekele-Tesemma A 2007 Useful trees of Ethiopia: identification, propagation and management in 17 agroecological zones. World Agroforestry Center, Nairobi, Kenya.

Fauna and Flora International 1995 The Proceedings of the Maputo WorkshopTowards Conservation and Responsible Use of Dalbergia melanoxylon.

Graphpad Instat 2003 GraphpadInstat software Inc., 306.

Kalonga SK, Midtgaard F and Klanderud K 2016 Forest certification as a policy option in conserving biodiversity: An empirical study of forest management in Tanzania. For. Ecol. Manag. 361: 1-12.

Katani JZ, Mustalahti I, Mukama K and Zahabu E 2016 Participatory forest carbon assessment in south-eastern Tanzania: experiences, costs and implications for REDD+ initiatives. Oryx 50(3): 523-532.

Malimbwi RE, Luoga EJ, Hofstad O, Mugasha AG and Valen JS 2000 Prevalence and standing volume of Dalbergia melanoxylon in coastal and inland sites of southern Tanzania. J. Trop. For. Sci. 12(2): 336-347.

Maundu PM and Tengnas T 2005 Useful trees and shrubs for Kenya. World Agroforestry Centre.

Mbuya LP 1994 Useful trees and shrubs for Tanzania. Swedish International Development Authority. Regional Soil Conservation Unit. Morogoro Platt, I.

Opulukwa MJ, Hamza K and Malende Y 2002 Inventory of Dalbergia melanoxylon (mpingo) in the Southern part of Tanzania: the case of Nachingwea. Afr. Study Monogr. 23(1): 1-10.

Sharman H 1995 Investigation into the sustainable management of a tropical timber species using Dalbergia melanoxylon as a case study. Master's thesis, University of Edinburgh.

TTSA 1995 Handling of seeds of Dalbergia melanoxylon (African Blackwood). Seed issue note No. 9.

Washa BW 2008 Dependence of Dalbergia melanoxylon natural population on root suckers regeneration. Asian J. Afr. Stud. 24: 177-198.

Washa WBA, Nyomora MS and Lyaruu HVM 2012 Improving propagation success of Dalbegia melanoxylon (African blackwood) in Tanzania (I): Characterization of mycorrhizal associated with D. melanoxylon (African blackwood) in Tanzania. Tanz. J. Sci. 38(1): 35-42.

Washa WB 2014 A review of the literature of Dalbergia melanoxylon. Int. J. Plant Forest. Sci. 1(1): 1-6.

Washa BW 2015 Potential of the dark as a factor affecting seed germination. Int. J. Sci. Technol. 5(2): 28-36. 